\title{
TRAINING DEPENDENT PROMOTIONS AND WASTAGES
}

\author{
V S S YADAVALLI \\ Department of Industrial \&Systems Engineering \\ University of Pretoria \\ R NATARAJAN \\ $S$ UDAYABHASKARAN \\ Department of Mathematics \\ Presidency College \\ University of Madras \\ Chennai, India
}

\begin{abstract}
An attempt is made in this paper to propose and analyse a stochastic model of a labour potential system incorporating training-linked promotions and wastages. A numerical example illustrates and highlights the findings
\end{abstract} of the model.

\section{OPSOMMING}

Hierdie artikel poog om ' $\mathrm{n}$ stogastiese model van 'n arbeidspotensiaalstelsel voor te stel en te ontleed waarin opleidingsverwante promosies en verlies van werkkragte geinkorporeer is. 'n Numeriese voorbeeld illustreer en lig die bevindinge van die model toe.

In many organizations, it is quite commonly found that promotion of staff from one grade to the next higher grade is linked to productivity improvement. But, one of the important criteria for promotion is the employee's up-to-date knowledge and technical skills for which training is required. Staff training is very important to developing organizations. For example, a nurse assisting in surgical operations may need to assist surgeons performing rare operations such as removal of brain tumor, heart transplantation etc., to gain additional experience which gives her an opportunity for further promotion. As another example, a computer software professional may come across several opportunities to be exposed to recent advances in the industry, and if these are utilised properly, he has an increased chance of being promoted to a higher cadre or of leaving the job for better opportunities. These examples indicate it is reasonable to assume that an employee may get one or more in-service training opportunities and thus becomes qualified to be promoted to the next higher grade; but, if promotion is not given to a trained person in due course, there is a chance that the person may leave the organisation either because of frustration or leaving the organization for better benefits and recognition of the acquired skills. Accordingly, depending of the amount of training undergone in the present grade, the employee may choose to remain in the organization, and possibly be promoted, or leave the organization. The impact of training on the movement of staff has not been given due importance in literature. The organization can expect more efficiency from their employee by giving him/her more training opportunities. This can positively impact on his/her career development. A manpower system with a single grade allowing wastages and recruitment was studied by Yadavalli and Natarajan (2001). Models considering the training aspect have been studied by Guardabassi et al. (1969), Purkiss (1969), Grinold \& Marshall (1977), Vajda (1978), Nakamura and Shingu (1984) and Goh et al. (1987). However, their objective is to minimize the reference cost or maximize the expected return for the planning period. Promotional policies to reduce wastages have been dealt with very extensively by Bartholomew (1967), Young and Vassiliou (1974) and Agrafiotis (1983, 1984, 1991). Not much work has

Requests for copies should be addressed to:VSS Yadavalli, Department of Industrial \& Systems Engineering, University of Pretoria, Pretoria, 0002 been done regarding training-linked promotions and wastages. A stochastic model of a manpower system incorporating these aspects is presented in this paper. The model assumptions and notation are given in Section 2 . The probability of remaining in the organization without promotion up to time $t$ and getting promotion in the interval $(t, t+\Delta)$ is derived in Section 3. The probability of remaining in the organization without getting promotion upto $t$ is obtained in Section 4. The probability distribution of the number of promotions received by an employee in $(0, t)$ is derived in Section 5. A numerical example is provided in Section 6 to illustrate the results obtained in the model.

\section{ASSUMPTIONS AND NOTATION}

We consider a manpower system which is graded hierarchically. An employee who enters into the system in a grade undergoes some kind of training before getting promoted to the next higher grade. The number of $n$ training opportunities/events that the employee may encounter while in service in a grade is unlimited and the rate of promotion depends on $n$. The employee with $n$ training already completed but not having got promotion yet may leave the organization either out of frustration or due to better monetary opportunity in a different organization. The employee may also leave the system due to other rare reasons arising out of medical grounds. Specifically, we made the following assumptions:

1. The epochs of trainings in one grade form a Poisson process with parameter $\lambda_{1}$.

2. The probability that a person gets promotion from a grade to the next higher grade in the interval $(t, t+\Delta)$ given that the employee had exactly $n$ training opportunities/events in that grade on hand at time t, is $n \mu_{2} \Delta$.

3. The probability that an employee leaves the organization due to dissatisfaction in the interval $(t, t+\Delta)$ given that the employee has exactly $n$ promotions on hand at time $t$, is $n \lambda_{2} \Delta$.

4. The probability that an employee leaves the organization in the interval $(t, t+\Delta)$ due to medical reasons is $v \Delta$.

5. The probability of more than one event occurring in $(t, t+\Delta)$ is $O(\Delta)$. 


\section{Notation:}

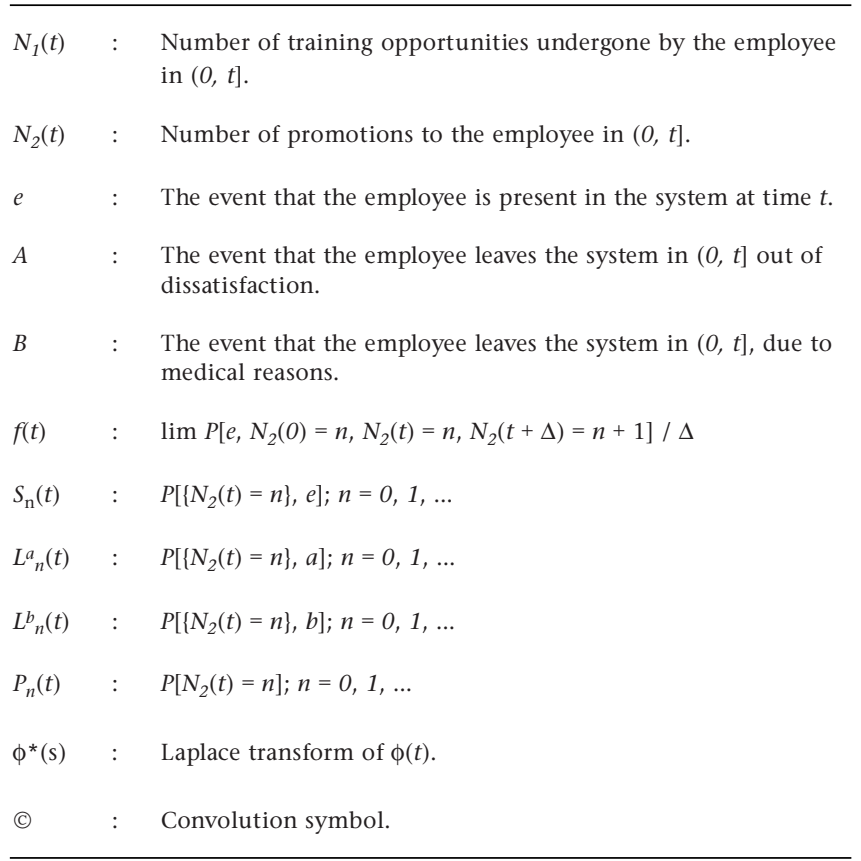

\section{EXPRESSION FOR $f(t)$}

$f(t)$ is the pdf of the interval between two successive promotions. In probabilistic terms, the quantity of $f(t) \Delta$ represents the probability that an employee waits in a grade $n$ without promotion upto time $t$ and gets promotion to $(n+1)^{\text {th }}$ grade in $(t, t+\Delta)$. Since at least one training should take place in $(0, t)$ and the employee should not leave the system for any reason whatsoever before a promotion can occur in $(t, t+\Delta)$, we have, by using probabilistic arguments,

$f(t)=e^{-\left(\lambda_{1}+v\right) t} \subseteq\left[\lambda_{2} e^{-\left(\lambda_{1}+v+\lambda_{2}\right) t}\right.$

$+\sum_{n=2}^{\infty}\left\{\lambda_{1} e^{-\left(\lambda_{1}+v+\lambda_{2}\right) t} \odot\left[\lambda_{2} e^{-\left(\lambda_{1}+v+\lambda_{2}\right) t} \odot \ldots \odot \lambda_{1} e^{-\left(\lambda_{1}+v+(n-1) \lambda_{2}\right) t} \odot \lambda_{2} e^{-\left(\lambda_{1}+v+n \lambda_{2}\right) t}\right\}\right]$

Taking $\mathrm{L}$ a place transforms both sides of (1), we obtain

$f^{*}(s)=\sum_{n=1}^{\infty} \frac{n \lambda_{1}^{n} \lambda_{2}}{\left(s+\lambda_{1}+v\right)\left(s+\lambda_{1}+v+\lambda_{2}\right) \ldots\left(s+\lambda_{1}+v+n \lambda_{2}\right)}$

Inverting (2), we get

$f(t)=\lambda_{1} \sum_{n=1}^{\infty} \frac{\left(\frac{\lambda_{1}}{\lambda 2}\right)^{n-1}}{n-1)} \sum_{j=0}^{\infty} n_{c_{j}}(-1)^{j} e^{-\left(\lambda_{1}+v+\lambda_{2}\right) t}$

Simplifying (3), we get

$f(t)=\lambda_{1} e^{-\left(\lambda_{1}+v\right) t}\left(1-e^{-\lambda_{2} t}\right) e^{\frac{\lambda_{1}}{\lambda 2}\left(1-e^{-\lambda_{2} t}\right)}$

\section{EXPRESSION FOR $S_{0}(t)$ :}

$\mathrm{S}_{0}(t)$ is the survivor function, which is the probability that an employee remains without promotion in the organization upto time $t$. Noting the fact that the employee might have received either no or one or more training $(0, t)$, we have

$\mathrm{S}_{0}(t)=e^{-\left(\lambda_{1}+v\right) t}+\lambda_{1} e^{-\left(\lambda_{1}+v\right) t} \odot e^{-\left(\lambda_{1}+v+\lambda_{2}\right) t}+\lambda_{1} e^{-\left(\lambda_{1}+v\right) t} \odot \lambda_{2} e^{-\left(\lambda_{1}+v+\lambda_{2}\right) t} \odot{ }^{-\left(\lambda_{1}+v+2 \lambda_{2}\right) t}$ $+\lambda_{1} e^{-\left(\lambda_{1}+v\right) t} \odot \lambda_{2} e^{-\left(\lambda_{1}+v+\lambda_{2}\right) t} \odot$
Taking the Laplace transforms on both sides and solve for $S^{*}{ }_{0}(S)$, we get

$$
S_{0}^{*}(s)=\sum_{n=0}^{\infty} \frac{\lambda_{1}^{n}}{\left(s+\lambda_{1}+v\right)\left(s+\lambda_{1}+v+\lambda_{2}\right) \ldots\left(s+\lambda+v+n \lambda_{2}\right)}
$$

Inverting (6), we get

$S_{0}(t)=e^{-\left(\lambda_{1}+v\right) t}+e^{\frac{\lambda_{1}}{\lambda 2}\left(1-e^{-\lambda_{2} t}\right)}$

\section{EXPRESSION FOR $P n(t)$ :}

By definition, $P_{n}(t)=P\left[N_{2}(t)=n\right] ; n=0,1, \ldots ;$ where $P_{n}(t)$ is the probability of getting $\mathrm{n}$ promotions. But the event $\left[N_{2}(t)=n\right]$ can be expressed as the union of three mutually exclusive and exhaustive events $\left[N_{2}(t)=n ; \quad e\right],\left[N_{2}(t)=n ; a\right], \quad\left[N_{2}(t)=n ; \quad b\right]$. Therefore

$P_{n}(t)=S_{n}(t)+L^{a}{ }_{n}(t)+L^{b}{ }_{n}(t)$

For finding $S_{n}(t), L^{a}{ }_{n}(t), L^{b}{ }_{n}(t)$, we need the following auxiliary functions

$S_{m, n}(t)=P\left[N_{1}(t)=m, N_{2}(t)=n ; e\right]$

$$
\begin{aligned}
\phi_{m, n}(t) & =\frac{\lim }{\Delta \rightarrow 0} \frac{1}{\Delta} P\left[N_{1}(t)=m, N_{2}(t)=n-1, N_{2}(t+\Delta)=n ; e\right] \\
\Psi_{m, n}(t) & =\frac{\lim }{\Delta \rightarrow 0} \frac{1}{\Delta} P\left[N_{2}(t)=m, N_{1}(t)=m-1, N_{2}(t+\Delta)=m ; e\right]
\end{aligned}
$$

Since $\phi_{\mathrm{m}, \mathrm{n}}(t) \Delta$ represents the probability that an employee remains in the system upto $t$, has undergone exactly $m$ training in $(0, t)$ and gets $n$th promotion in $(t, t+\Delta)$. Therefore

$\phi_{m, n}(t)=\sum_{r=1}^{m-n+1} \phi_{m-r, n-1}(t) \circlearrowleft q_{n}^{(r)}(t) \odot m \lambda_{2} e^{-\left(\lambda_{1}+m \lambda_{2}+v+n \mu\right) t}$

where $\mathrm{q}^{(\mathrm{r})}{ }_{\mathrm{n}}(t)$ is $\underline{\mathrm{r}}$-fold convolution of $\lambda_{1} e^{-(\lambda+v+n \mu) t}$. In the same way,since $\psi_{\mathrm{m}, \mathrm{n}}(t) \Delta$ represents the probability that an employee remains in the system upto $t$, has obtained $n$ promotions and goes for $m$ th training in $(t, t+\Delta)$, we get

$\Psi_{m, n}(t)=\Psi_{m-n, n}(t) \Subset \lambda_{1} e^{-\left(\lambda_{1}+v+n \mu\right) t}+\phi_{m-1, n}(t) \odot \lambda_{1} e^{-\left(\lambda_{1}+v+n \lambda_{1}\right) t}$

Now, we can readily obtain $S_{m, n}(t)$,

$S_{m, n}(t)=\left\{\phi_{m, n}(t)+\psi_{m, n}(t)\right\} \Subset e^{-\left(\lambda_{1}+v+n \mu\right) t}$

using $S_{m, n}(t)$, we get

$S_{n}(t)=\sum_{m=0}^{\infty} S_{m, n}(t)$

$L_{n}^{a}(t)=\sum_{m=00}^{\infty} \int_{m, n}^{t} S_{m}(u) n \mu d u$

$L_{n}^{b}(t)=\sum_{m=00}^{\infty} \int_{m, n}^{t} S_{m}(u) v d u$

\section{NUMBERICAL ILLUSTRATION}

We present in Table 1 , the values of $S_{0}(t)$ for the values of the parameters given in Agrafiotis (1984) with $\lambda_{1}=\lambda_{2}=\lambda$. From the table we find that the probability of remaining in the system without promotion decreases as time progresses.

\section{CONCLUSIONS}

This paper is a study of the link between promotion and the amount of training, and obtains, analytically, the chance for an 
employee to remain in the organization without being promoted up to time $t$. A numerical illustration for $S_{0}(t)$, answers the important question raised in the motivation of the paper. If the empirical data is available, the results given in the paper can be used to obtain important measures such as mean time to promotion, for a practical human resource management problem.

TABLE 1

Probability $\boldsymbol{S}_{0}(\mathrm{~T})$

\begin{tabular}{ccccc}
\hline $\begin{array}{c}\text { Time } \\
\boldsymbol{T}\end{array}$ & \multicolumn{4}{c}{ Probability $\mathrm{S0}(\mathrm{t})$} \\
\hline & $\lambda=0,839, v=$ & $\lambda=0,805, v=$ & $\lambda=0,382, v=$ & $\lambda=0,576, v=$ \\
& 0,378 & 0,383 & 0,116 & 0,332 \\
0 & 1,00000 & 1,00000 & 1,00000 & 1,00000 \\
1 & 0,52249 & 0,52989 & 0,83486 & 0,62491 \\
2 & 0,19775 & 0,20682 & 0,63015 & 0,32239 \\
3 & 0,06511 & 0,07041 & 0,44401 & 0,14932 \\
4 & 0,02018 & 0,02255 & 0,29850 & 0,06510 \\
5 & 0,00610 & 0,00703 & 0,14435 & 0,02743 \\
10 & 0,00001 & 0,00002 & 0,01828 & 0,00031 \\
20 & 0,0000 & 0,00000 & 0,00013 & 0,00000 \\
30 & - & - & 0,00001 & - \\
40 & - & - & 0,00000 & - \\
\hline
\end{tabular}

\section{REFERENCES}

Agrafiotis, G.K. (1983) A two stage stochastic model for labour wastage. European Journal of Operational Research, 5, 128-B2.

Agrafiotis, G.K. (1984) A grade specific stochastic model for the analysis of wastage in manpower systems. Journal of Operational Research Society, 35, 549 - 554.

Agrafiotis, G.K. (1991) On the stochastic theory of compartment: The general time dependent two compartment reversible systems with an application to manpower planning. Journal of Operational Research Society, 47, 587 - 594.

Bartholomew, D.J. (1967) Stochastic models for social processes: $2^{\text {nd }}$ Edition. Chichester: John Wiley.

Goh, C.J., Teo, K.L. and Goh, T.N. (1987) Optimal planning of manpower training programmes. Opsearch, 24, 240 - 248.

Grinold, R.C. and Marshall, K.T. (1977) Manpower planning models. New York : North Holland.

Guardabassi, A., De Maio Locatelli, A. and Rinaldi, S. (1969) Optimal manpower training computing methods in optimization problems. Lecture Notes in Operations Research and Mathematical Economics; RN4; Springer-Verlag; Berlin.

Nakamura, N. and Shingu, T., (1984) A model for recruiting and training decisions in manpower planning. International Journal of Production Research, 22, 1 - 15.

Purkiss, C.J. (1969) Approaches to recruitment policies. Journal of Operational Research Society, 41, 983 - 988.

Vajda, S. (1978) Mathematics of manpower planning. Chichester: John Wiley.

Yadavalli, V.S.S. and Natarajan, R. (2001) A semi-Markov model of a manpower system. Stochastic Analysis and Applications 19, 1077-1086.

Young, A. and Vassiliouv, P.C.G. (1974) A non-linear model on the promotion of staff. Journal of Royal Statistical Society, Series A, 137, $584-595$. 